\title{
A NOTE ON THE MORPHOLOGY OF THE SEMINIFEROUS TUBULES OF BIRDS
}

\author{
G. CARL HUBER
}

Department of Anatomy, University of Michigan

ONE FIGURE

In the course of a study of the renal tubules of birds, by means of the maceration method devised by Huber, ${ }^{1}$ in which full grown roosters (Gallus domestica) were used as material, the injection of the 75 per cent solution of hydrochloric acid was through the aorta central to the branches supplying the kidneys and sex glands. In a number of the cases the testes were found to be well injected and were removed and placed in 75 per cent hydrochloric acid with a view of obtaining thorough maceration preparatory to teasing. Following the method as described, the macerated pieces were washed thoroughly in distilled water, stained in hemalum, softened and cleared in 0.25 per cent to 0.5 per cent ammonia water, in which they were teased.

Even during the preliminary teasing of the larger pieces it was noted that the testis of the rooster was not separable into lobular masses, as is the case in mammalian testes, so that it was found impossible to isolate structural units with which the final teasing could be carried out.

Huber and Curtis ${ }^{2}$ found that in the mammalian testis the seminiferous tubules presented no blind ends, diverticuli or nodular enlargements but were arranged in the form of an arch or a variable number of linked arches, all of the ends terminating

${ }^{1}$ Huber, G. Carl. A method for isolating the renal tubules of mammalia. Anat. Ree., vol. 5, 1911.

${ }^{2}$ Huber, G. Carl, and Curtis, George Morris. The morphology of the seminiferous tubules of mammalia. Anat. Rec., vol. 7, 1913. 
in tubuli recti attached to the rete testis. Wax reconstructions made by Curtis confirm the observations made on teased preparations. Repeated teasings have convinced me that in the adult bird no such arrangement of tubules pertains, but that the seminiferous tubules of the bird are arranged in the form of a network, presenting a varying number of anastomoses found at different levels in the gland substance. For this reason the teasing of these tubules is exceedingly difficult in that it is impossible without breaking or tearing tubules to separate favorable pieces preparatory to final teasing. All of my teased preparations present an endless net, with broken tubular ends as a boundary.

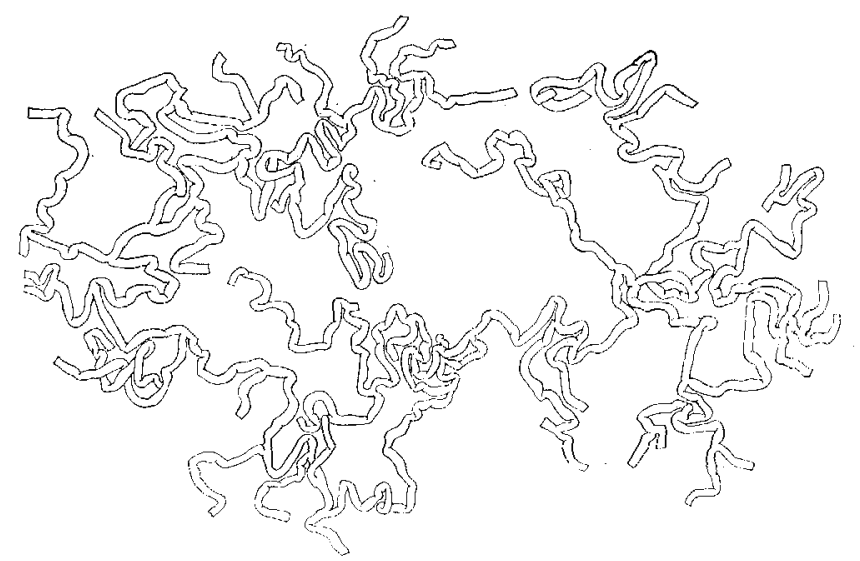

Fig. 1 Teased preparation showing a portion of the tubular system of the testis of the bird (Gallus domestica). $\times \mathbf{5}$.

In the accompanying figure is presented one of the most successful preparations obtained. The figure was traced and sketched with the aid of the camera lucida at a magnification of 50 diameters, reduced to a magnification of 5 diameters in the reproduction. The portion of the tubular net reproduced presents in all some forty broken ends, and at least three closed rings. Such closed rings I have found in nearly all of my preparations. Their complete separation requires great care and patience since uniting tubular portions are very easily broken. The clearness of the figure, it is thought, obviates the necessity 
of extended description of the character of the network formed by the seminiferous tubules of birds. The figure, however, should be studied with the understanding that in the mount from which the figure was drawn the teased tubules were spread out as much as possible. The figure, therefore, does not give spatial relations of the tubules. In the gland, as is well known, these tubules form compact coils, evident somewhat from the extended kinks and bends seen in the figure.

In a rather careful search of the literature I have been unable to find any description of the form of the seminiferous tubule of birds. This note would thus seem justified. However, the observations here recorded would seem to me to have a bearing on previous work emanating from this and other laboratories, relating to the form of the seminiferous tubules of mammalia. The results here recorded seem to me to confirm the observations made on teased preparations of the seminiferous tubules of mammals. The fact that complex anastomoses resulting in closed ring structures have been teased in the bird's testis argues for the possibility of teasing such structures in the adult mammalian testis, did they exist. Bremer, ${ }^{3}$ as a result of careful wax reconstructions of the tubular system of the human testis, working on embryonic and fetal tissue, the oldest stage studied being that of a human fetus of seven months, reached the conclusion that

The testis cords, growing from the germinal epithelium of the genital ridge, form a network with three sets of anastomosing branches. After completion, this network breaks down partially, leaving certain cords as persistent stems. The tubules of the adult show, in their course, connection, and position in the testis, traces of this network. Testis tubules may be single, ending blindly, may branch, or may anastomose.

In the adult mammalian testis tubules, completely teased, no blind endings, buds, nor ring formations were observed, while in the teased preparations of the seminiferous tubules of birds, the remains of the network of tubules as observed in the embryonic and fetal stages and well figured by Bremer, may be

\footnotetext{
${ }^{3}$ Bremer, John Lewis. The morphology of the tubules of the human testis and epididymis. Amer. Jour. Anat., vol. 11, 1911.
} 
noted. In a cryptorchid of the rabbit, as described by Huber and Curtis, extended anastomoses of testis tubules were observed in two regions of the tubule complex, and in two regions, near the periphery of the gland, tubules were joined so as to form two folded rings. The preparations from the cryptorchid of the rabbit present appearances not unlike those shown in teased preparations of the seminiferous tubules of the bird. The presence of the remains of the embryonic network of the seminiferous tubules in the cryptorchid of the rabbit and in the bird's testis, postulates a relatively late, complete morphogenesis of the seminiferous tubules of the mammal. Phylogeny and ontogeny indicate this. In the light of these observations I am of the opinion that Bremer's careful study of the morphology of the seminiferous tubules of the human testis are of value as concerns embryonic and late fetal stages, but may not be transmitted to the adult gland in that in the oldest stage studied, a human fetus of the seventh month, the seminiferous tubules, in all probability, had not completed their morphogenesis. The question is one deserving further study and will form the subject of a future, more comprehensive communication, based on especially prepared and 'timed' material from the rabbit. This form is chosen since the morphology of the seminiferous tubule of the adult rabbit has received special consideration in this laboratory, both by means of teased preparations and reconstructions. 